\title{
Review Study on the Accumulation and Release of Trace Metal Elements on Aluminum Containing Sediments in Drinking Water Distribution System
}

\author{
Xiaoni ZHANG ${ }^{1}$, Jinghua MENG ${ }^{1}$, Li CHEN $^{1}$, Huanhuan $\mathrm{ZUO}^{1}$, Wendong WANG ${ }^{2}$ \\ 1 School of Civil Engineering, City College of Science and Technology Chongqing University, Chongqing, China \\ 2 School of Human Settlements and Civil Engineering, Xi'an Jiaotong University, Xi an, China
}

*Corresponding Author: Wendong WANG, No.28, Xianning West Road, Xi an, Shannxi, 710049, China; wdwang@xjtu.edu.cn

\begin{abstract}
:
Accumulation and releasing of trace metal elements on aluminum containing sediments of inner drinking water pipe is discussed, as studied from five variations effecting: raw water quality, chemical reagents, solution $\mathrm{pH}$ and drinking water flow condition . In order to decrease the release of trace metal elements, and to ensure the pipe operation and human safety, water quality adjustment is suggested to avoid aluminum containing sediments formation in drinking distribution system. The maximum amounts of accumulation of common trace metal elements are given. Future trends of development in this field are also proposed.
\end{abstract}

Keywords: drinking water distribution system; aluminum containing sediments; trace metal elements; accumulation; release

\section{Introduction}

There are serious corrosion and deposition on the inner wall of water supply network. Scale deposits containing aluminum (aluminum) on the pipeline corrosion and the release of pollutants plays a protective role, as well as a variety of trace metal elements important substrate adsorption accumulation, have a positive impact on water supply security ${ }^{[1]}$. However, sudden release of metal elements may occur when water quality conditions change or sediment structures are damaged. As a result of trace metal elements in pipe network in the sediment accumulation and sudden release has caused a serious impact on the health of residents drinking water ${ }^{[2]}$, the attention of the safety of drinking water is one of the change of the water treatment process, make the existing network of aluminized sediments off the steady probability and harm degree.

\section{Accumulation and release of trace metal ions by aluminum-containing deposits}

2.1 Accumulation of metal ions by aluminum-containing deposits

Aluminum deposits can effectively store various metallic elements under the action of adsorption and coprecipitation. Taking lead ion as an example, before aluminum salt was used for coagulation treatment, the lead ion concentration in the Hemlock waterworks was $15-38 \mu \mathrm{g} / \mathrm{L}$. two and a half months after the use of aluminum salt, the concentration of lead ions in the effluent can be decreased to $5-15 \mu \mathrm{g} / \mathrm{L}$, the $\mathrm{pH}$ of the solution is relatively stable in the process. At the same time, with the decline of water distribution capacity of the pipe network. The composition analysis shows that there are a lot of aluminum elements in the sediments, mainly silica-aluminate.

The accumulation of trace metal elements in pipe network sediments is related to factors such as sampling location, pipeline material and corrosion degree (Table 1). The contents of arsenic, aluminum and zinc in copper pipe sediments were $2100 \mathrm{mg} / \mathrm{kg}, 68-200 \mathrm{mg} / \mathrm{kg}$ and $52-6510$ $\mathrm{mg} / \mathrm{kg}$ respectively, while the contents in lead pipe were $229 \mathrm{mg} / \mathrm{kg}, 36,000 \mathrm{mg} / \mathrm{kg}$ and $36900 \mathrm{mg} / \mathrm{kg}$ respectively. At the same time, the storage capacity of metal elements in the sediments formed by the same pipe in different pipe network systems is quite different.

\subsection{Destabilization release of metal ions}

Most metal ions can be stored in the pipe network by physical and chemical actions such as adsorption, precipitation and coprecipitation. However, as a large reservoir of various pollutants, changes in hydraulic and water quality conditions may also have adverse effects on its stability, leading to the sudden release of pollutants 
${ }^{[21-22]}$.A pipe network system in Wales, England, no used lead pipe material, a large number of metal elements such as lead, copper, zinc and tin was detected in the water of the pipe network ${ }^{[23]}$. Investigation revealed inside the pipe wall there is a layer of green pipe scale, main ingredients for aluminum $(68-200 \mathrm{mg} / \mathrm{kg})$, lead $(574-2940 \mathrm{mg} / \mathrm{kg})$, chromium (32-112 mg/kg), tin (11-273 mg/kg), cadmium (5.4 mg/kg), antimony (0.4 $1.7 \mathrm{mg} / \mathrm{kg})$, zinc (52-510 mg/ $\mathrm{kg}$ ). When the coagulant was changed from aluminum salt to iron salt, the composition of the aluminum-containing sediments changed accordingly. Considering the safety of water supply and residents' drinking water, it is necessary to investigate the influence of changes in water hydraulic and quality conditions on the stability of aluminum deposits in the pipe network and the release characteristics of various trace elements.

Table 1. Summary of the characteristics of aluminum containing sediments and their adverse effects researched in published studies

\begin{tabular}{lll}
\hline Study Date Observation & Ref. \\
\hline
\end{tabular}

Baylis

Hudson

1966

Cooper \& Knowles

Hoff

McGinn \& Briggs

Qureshi \& Malmberg

Fitch \& McCollum

Zimmerman

Fuge et al.

Shea

Lauer \& Lohman

Kriewall et al.

Kirmeyer et al.

Havics

Snoeyink et al.

2003

Schock et al.

USEPA
After the South District Filtration Plant was put in operation, a soft gelatinous coating was formed in the pipe line. It consisted mainly of aluminum hydroxide, with considerable silica.

Regardless of the type of pipe material, when coagulation and filtration operation was not proper, aluminum hydroxide could be formed. Very thin aluminum deposits could reduce its carrying capacity notably.

Within 5 years operation, $2 \mathrm{~mm}$ thick whitish-grey substance formed on the pipe surface of a 42 -inch main in London. The sediments were mostly amorphous interspersed with fine silica, and composed by $20-23 \% \mathrm{Al}_{2} \mathrm{O}_{3}, 25-40 \% \mathrm{SiO}_{2}, 4-8 \% \mathrm{CaO}, 6-10 \% \mathrm{MgO}, 3-10 \% \mathrm{Fe}_{2} \mathrm{O}_{3}$.

Aluminum phosphate particles and clay were believed to be representative particles in many drinking water distribution systems.

Slimy deposits, containing $80-90 \%$ aluminum, with small amounts of iron, magnesium, silica and organic carbon, were found in the pipe line.

Aluminum post precipitation occurred in the distribution mains of Fridley Filtration Plant, Minneapolis, Minnesota.

A $10 \mathrm{~mm}$ thickness gelatinous precipitate that composed predominantly of aluminum and silicon oxide was found, which might contribute to the rapid loss in transmission capacity.

Increased energy consumption and approximately 25\% loss of transmission capacity accompanied the aluminum containing sediments precipitation. When the drinking water $\mathrm{pH}$ increased, it would become unstable.

Reduction in finished water $\mathrm{Al}$ concentration caused soluble and particulate aluminum release from a in a Wales distribution system network and domestic piping.

A white powder scale was discovered in Green Bay, Wisconsin pipe line. Laboratory analysis indicated that it was mainly aluminum silicate. The addition of orthophosphate did not cause any improvement.

The main sediment composition of Denver distribution system, storage reservoir and lead pipe wall were $36-42 \% \mathrm{Al}_{2} \mathrm{O}_{3}, 24-29 \% \mathrm{SiO}_{2}, 1-3 \% \mathrm{CaO}$.

The transmission capacity decreased notably after a new filtration plant put into operation, which might connected with the aluminum containing colloidal or particles.

Reddish and reddish-grey deposits were found in the control loop of pipe. Analysis of the material showed $15 \% \mathrm{Al}$ and $50 \%$ organic matter on a dry basis.

The white precipitates formed in the drinking water distribution system of Georgia contained substantial concentrations of aluminium and phosphorus, and sometimes associated with $\mathrm{Si}, \mathrm{Fe}$ and other elements.

Summarized the sources and characteristics of aluminium containing sediments, and presented new data on the elemental composition of scales found in selected systems in the USA.

Pointed out that the accumulation of inorganic pollutants, including aluminum should be received much attention. Their suddenly release was as serious as that caused by organic matters.

Summarized aluminum containing sediments and other sediments accumulation in drinking water supplying system, their effects on drinking water quality, and factors affecting pollutants accumulation and release. 
Table 2. Summary of trace metal elements accumulation occurrences in published studies

\begin{tabular}{|c|c|c|c|c|}
\hline Contaminant & Sample Source & $\begin{array}{l}\text { Contaminant } \\
\text { concentration }(\mathrm{mg} / \mathrm{kg})\end{array}$ & $\begin{array}{l}\text { Potential for MCL exceedance } \\
\text { (mg scale or sediment per litre) }\end{array}$ & Ref. \\
\hline \multirow{6}{*}{ Antimony } & Lead line & 100 & 60 & 18 \\
\hline & Flush water & 0.027 & - & 19 \\
\hline & Reservoir sediment & 48 & 125 & 20 \\
\hline & Lead line & 229 & 44 & 18 \\
\hline & Flush water & 0.151 & - & 19 \\
\hline & Reservoir sediment & 300 & 33 & 20 \\
\hline Barium & Lead line & 88 & 22700 & 18 \\
\hline \multirow{2}{*}{ Beryllium } & Lead line & 460 & 8.7 & 18 \\
\hline & Lead line & 290 & 13.8 & 18 \\
\hline Cadmium & Lead line & 76.8 & 65.1 & 18 \\
\hline Chromium & Lead line & 65.4 & 1529 & 18 \\
\hline \multirow{4}{*}{ Copper } & Lead line & 350 & 3714 & 18 \\
\hline & Lead line & 1100 & 182 & 18 \\
\hline & Flush water & 1.37 & - & 19 \\
\hline & Reservoir sediment & 830 & 18.1 & 20 \\
\hline Mercury & Lead line & 1.24 & 1613 & 18 \\
\hline Selenium & Lead line & 7.8 & 6410 & 18 \\
\hline Thallium & Lead line & 12.7 & 157 & 18 \\
\hline \multirow{2}{*}{ Aluminum } & Lead line & 121000 & $0.41-1.65$ & 18 \\
\hline & Lead line & 36000 & $1.4-5.6$ & 18 \\
\hline Nickel & Lead line & 164 & 610 & 18 \\
\hline Silver & Lead line & 1.3 & 76900 & 18 \\
\hline Vanadium & Lead line & 182 & - & 18 \\
\hline \multirow{2}{*}{ Zinc } & Lead line & 36900 & 135.5 & 18 \\
\hline & Reservoir sediment & 13000 & 385 & 20 \\
\hline Rare Earth & Lead line & 4478 & - & 18 \\
\hline Elements & Lead line & 794 & - & 18 \\
\hline
\end{tabular}

2.2.1. Influence of water flow status

The rapid change of the flow conditions, such as pipe flushing, peak flow and fire flow may damage the structure stability of the sediment, cause the release of trace metal elements, and the change range of flow and sediment state of aggregation on the release of aluminum content has an important influence. When the flow rate increases from $1.7 \mathrm{~m} / \mathrm{s}$ to $1.9 \mathrm{~m} / \mathrm{s}$, loose deposits with large sand content in the pipe network can enter the main water phase in the form of suspended state. For loose deposits with high content of metal elements, the flow velocity should be increased from $1.9 \mathrm{~m} / \mathrm{s}$ to $4.0 \mathrm{~m} / \mathrm{s}$ to achieve the same scouring effect. When the flow rate increases to over $4 \mathrm{~m} / \mathrm{s}$, the scale on the pipe wall and some pipe materials will also enter the water ${ }^{[24]}$. Experience showed that the traditional hydrant flushing technology is undesirability for removing impurities in pipelines including aluminum deposits due to the reciprocating change of flow direction, while one-way flushing removed most of the sediment. In addition, the structural characteristics of sediments have some influence on their stability. Due to oxidation, corrosion and other effects of the formation of benign tumors, pipe scale and other structures relatively stable, the flow rate and flow direction change less impact on it; aluminum deposits are more prone to structural damage.

\subsubsection{Effects of raw water quality}

The water quality of most surface water bodies is characterized by seasonal variation. In addition, in the season with high turbidity, groundwater is often used to replace surface water sources. The difference in water quality between water sources will also lead to changes in water quality of water supply. When the water quality of raw water fluctuates greatly, if the water purification process cannot be adjusted in a timely manner, the chemical stability of the pipe network sediments will be damaged and a large number of metal elements will be released. Before 1990 , a water system in central Wales used surface water as its source. The concentration of aluminium ions in raw water is between $0.15 \mathrm{mg} / \mathrm{L}$ and $0.30 \mathrm{mg} / \mathrm{L}$. Considering the high residual aluminum content in the treated water, a centralized cleaning of the pipe network was carried out in 1990, and the water source was switched to groundwater 
with low aluminum content. The residual aluminum concentration in the pipe network decreased significantly after the water source was switched over. However, with the increase of water transmission distance, the concentration gradually increased. When the water delivery distance is 3.1 miles, the aluminum ion concentration in the pipe network is $0.017 \mathrm{mg} / \mathrm{L}$. The aluminum ion concentration was $0.05 \mathrm{mg}$ $/ \mathrm{L}$ after the water delivery distance increased to 11.2 miles, indicating that there was the release of aluminum ion in the pipeline sediments, and the water source switching process damaged the stability of the original aluminum pipe scale [23].

\subsubsection{Effect of solution $p H$}

Under short-term water supply conditions, the $\mathrm{pH}$ of the solution fluctuate within $0.5 \mathrm{pH}$ units. $\mathrm{PH}$ fluctuation is more pronounced during seasonal changes or when water is switched. In order to improve the treatment efficiency of coagulation precipitation and reduce the corrosion of metal pipes in the process of water distribution, some water plants still need to adjust the $\mathrm{pH}$ of the treated water. When $\mathrm{pH}$ changes by more than $1 \mathrm{pH}$ unit, aluminum deposits deposited in pipes such as lead pipes, copper pipes and iron pipes will be destroyed, resulting in the release of metal ions ${ }^{[26]}$. Munk et al. believed that the minimum $\mathrm{pH}$ change of metal ions in aluminium-containing sediments was about $0.2 \mathrm{pH}$ units. Therefore, even under the normal $\mathrm{pH}$ condition of water distribution, the release of zinc, copper, nickel, molybdenum, cadmium and other elements still exists ${ }^{[27]}$. Kendall partial correlation analysis showed that the adsorption of metal ions, such as copper and chromium, on the surface of sediments is mainly related to the content of aluminum in sediments, but is less affected by iron and manganese ${ }^{[28]}$. a)

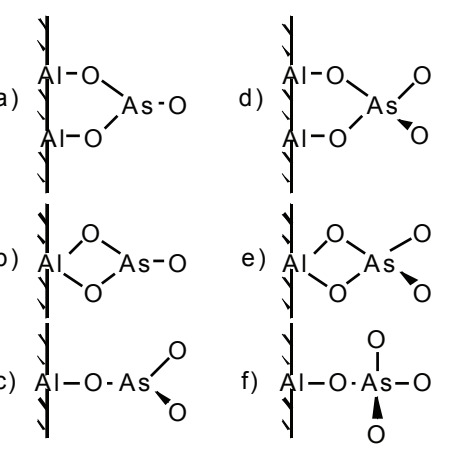

Figure 1. Molecular configurations of $\mathrm{As}(\mathrm{III})$ and $\mathrm{As}(\mathrm{V})$ inner-sphere surface complexes ${ }^{[25]}$

The storage and release of arsenic in sediments is related to its valence state and solution $\mathrm{pH}^{[2]}$. When the $\mathrm{pH}>5.5$, trivalent arsenic and amorphous aluminum hydroxide surface between the outer and inner layer with two kinds of combination way, and with the ionic strength of solution is reduced, the outer with more pronounced; When the $\mathrm{pH}$ value is less than 5.5, the inner layer coordination modes, such as dual-teeth dual-core, dualteeth monocytes and single-tooth monocytes, are mainly adopted (figure 1). As the $\mathrm{pH}$ of the solution increases, the binding capacity of the two increases continuously, which is conducive to the storage and precipitation of arsenic trivalent. The combination of arsenic pentavalent and amorphous aluminum hydroxide is mainly the inner double dentate biconuclear coordination, the adsorption strength of arsenic on the solid surface decreases with the increase of $\mathrm{pH}$.

\subsubsection{Use of chemical agents}

The use of polyphosphates and other masking agents can effectively increase the chemical stability of iron, calcium, aluminum, manganese, magnesium and other metal ions and reduce the formation of pipeline sediments. The enhanced solubility will destroy the chemical stability of existing aluminum-bearing sediments, leading to the desorption and redissolution of trace metal elements. For the water distribution system using asbestos-cement pipe, under the competition and softening effect of polyphosphate, the aluminum precipitation of pipeline material is serious. In order to prevent corrosion of metal pipes, orthophosphate is often added to the treated water. Davis et al. investigated the effect of corrosion inhibitors such as orthophosphate on metal ion release in the actual pipe network by using simulation system, the concentration of arsenic in the main flow is $0.010 \mathrm{mg} / \mathrm{L}$, after 3 hours of stable operation, $1 \mathrm{mg} / \mathrm{L}$ of orthophosphate was added at the inlet of the pipe network, it was found that the arsenic content in the outlet water of the pipe network increased significantly after the addition of orthophosphate, 1.6 to 15 times of the background concentration and up to $1.5 \mathrm{mg} / \mathrm{L}^{[29]}$.

\section{Conclusions and prospects}

Deposits containing aluminum is very common in the pipe network under the effect of adsorption and coprecipitation and other physical and chemical, for the accumulation of the trace metal elements in the water has obvious effect, and when the raw water quality, water treatment agent, pipe network water $\mathrm{pH}$ and flow state changes, will damage deposits containing aluminum structure stability, can cause a sudden release of trace metal elements. Based on the review of previous work, this paper gives the control release quantity within the scope of acceptable concentration, trace metal elements in the sediments of the maximal common allow volume (Table 2). It is suggested that the production of aluminum-containing sediments should be controlled to reduce the amount of metal elements accumulated and to reduce the water quality impact caused by the sudden release of metal elements. However, as an important part of pipeline sediment in water distribution system, the existing literature mainly comes from the operation and management practice of water plants. The related test phenomena and research conclusions are mostly based on lead pipe and copper pipe, and less attention is paid to iron pipe, steel pipe and other iron pipe materials. And the pipe network of more than $90 \%$ are made by cast iron pipe and stainless steel pipe laying, appeared on deposits containing aluminum and the water quality deterioration caused by the report is far less than is given priority to with lead 
tube and copper tube, the formation mechanism of proven deposits containing aluminum as well as the influence on the process of piping material way will be the development direction in the future.

Author Contributions: Co-author Wen-dong WANG is the main director of the researcher project, including the study objective and its significance. The first author Xiaoni ZHANG is in charge of analyzing characteristics of accumulation and release of trace metal to aluminum containing scale in drinking water pipe, Jing-hua MENG, Li CHEN and Huan-huan ZUO are in charge of finding and references.

Conflict of Interest: The authors declares that there is no conflict of interest regarding the publication of this paper.

Acknowledgments: This work was supported by City Collage of Science and Technology. Chongqing University and Chongqing HaiRun institute of energy saving research.

\section{References}

[1] Snoeyink V L, Schock M R, Sarin P, et al. Aluminumcontaining scales in water distribution systems: Prevalence and Composition. Journal of Water Supply: Research and Technology - AQUA, 2003, 52(7):455-474

[2] Schock M R. "Distribution Systems as Reservoirs and Reactors for Inorganic Contaminants." Ch.6 in: Distribution System Water Quality Challenges in the 21st Century. Denver, CO: American Water Works Association, 2005. 105-140

[3] Baylis J R. J. Cast-iron pipe coatings and corrosion. Am. Wat. Wks Assoc., 1953, 45(8):807-822

[4] Cooper R E, Knowles W L. Loss in capacity of a large diameter water pipeline. American Water Works Association 95th Annual Conference. Minneapolis, Minnesota: American Water Works Association Research Foundation, 1975. 2-3

[5] Hudson W D. J. Am. Wat. Wks Assoc., 1966, 58(2):157164

[6] Hoff J C. The relationship of turbidity to disinfection of potable water. Evaluation of the Microbiology Standards for Drinking Water. Washington, DC: US Environmental Protection Agency, 1978

[7] McGinn R A, Briggs B. Am. City \& County, 1979:49-53

[8] Qureshi N, Malmberg R H. J. Am. Wat. Wks Assoc., 1985, 77(10):101-108

[9] Fitch D E, McCollum G. R. J. Am. Wat. Wks Assoc., 1986:35-38

[10] Zimmerman J A. AWWA Seminar on Water Quality Concerns in the Distribution System. Denver, Colorado: American Water Works Association, 1986. 41-70

[11] Fuge R, Pearce N J G, Perkins W T. Unusual sources of aluminum and heavy metals in potable waters. Environ. Geochem. Health, 1992, 14(1):15-18
[12] Shea R D. 'Pig' cleaning water transmission pipelines. Publ. Wks, 1993, 124:54-59

[13] Lauer W C, Lohman S R. American Water Works Association Water Quality Technology Conference. San Francisco, California: American Water Works Association, 1994. 1753-1760

[14] Kriewall D, Harding R, Naisch E, et al. Publ. Wks, 1996, 127(12):28-30, 67

[15] Kirmeyer G J, Pierson G, Clement J, et al. Distribution System Water Quality Following Corrosion Control Strategies. Denver, Colorado: American Water Works Association Research Foundation, 1999

[16] Havics A A. Microscope, 2001, 49(1):1-8

[17] USEPA. Inorganic Contaminant Accumulation in Potable Water Distribution Systems. Office of Groundwater and Drinking Water, 2006

[18] Schock M R. Proceedings Inorganics Contaminants Workshop, Reno, NV, 2004

[19] Clement Bob, Carlson G. Inorganic Contaminants Workshop. Reno, Nevada: AWWA, 2004

[20] Scanlan L. Distribution system water quality changes: A challenge. Annual conference and exposition. Denver, Colorado: American Water Works Association, 2003

[21] Dodge D J, Francis A J, Gillow J B, et al. Association of uranium with iron oxides typically formed on corroding steel surfaces. Environ. Sci. Technol., 2002, 36:35043511

[22] USEPA. Potential contamination due to crossconnections and backflow and the associated health risks - an issues paper. USEPA, Office of Groundwater and Drinking water, (8/3/2004).

[23] Fitch D E, McCollum G. R. J. Am. Wat. Wks Assoc., 1986:35-38

[24] Friedman M J, Kathy M, Andrew H, et al. Establishing SiteSpecific Flushing Velocities. Denver, Colorado: American Water Works Association Research Foundation, 2003

[25] Havics A A. Microscope, 2001, 49(1):1-8

[26] Munk L, Faure G. Appl. Geochem., Effects of $\mathrm{pH}$ Fluctuations on Potentially Toxic Metals in the Water and Sediment of the Dillon Reservoir, 2004, (19):10651074

[27] Chen J, Wang F. GeoJournal, Chemical composition of river particulates in eastern China. 1996, 40:31-37

[28] Copeland R, Dionysiou D. Arsenic desorption from drinking water distribution system solids and iron/ activated alumina based column media. Proceedings of the 2005 AWWA Annual Conference. San Francisco, 2005

[29] Arai Y J, Evert J E, Donald L S. Journal of Colloid and Interface Science, 2001, 235:80-88 